\title{
Development of Students' Research Activity During Studying at Higher Education Institutions
}

\author{
ANASTASIIA BESSARAB ${ }^{1}$, VOLODYMYR SADIVNYCHYI ${ }^{2}$, ALLA ILCHENKO 3 , \\ GALYNA RIPKA ${ }^{4}$, VALENTYNA SHAPOSHNIKOVA ${ }^{5}$, ELVIRA TAINEL ${ }^{6}$ \\ ${ }^{1}$ Department of Special Pedagogy and Special Psychology, MUNICIPAL INSTITUTION OF HIGHER EDUCATION \\ «KHORTYTSIA NATIONAL EDUCATIONAL REHABILITATION ACADEMY», UKRAINE, \\ E-mail: bessarab_a@meta.ua. \\ ${ }^{2}$ Department of Journalism and Philology, SUMY STATE UNIVERSITY, UKRAINE. \\ ${ }^{3}$ Department of Humanitarian and Social Disciplines, POLTAVA STATE AGRARIAN ACADEMY, UKRAINE. \\ ${ }^{4}$ Department of Light Industry Technologies, VOLODYMYR DAHL EAST UKRAINIAN NATIONAL UNIVERSITY, \\ UKRAINE. \\ ${ }^{5}$ Department of Professional Medical and Pharmaceutical Disciplines, CHERKASY MEDICAL ACADEMY, \\ UKRAINE. \\ ${ }^{6}$ Depatment of Muzical Arts, IVAN FRANKO NATIONAL UNIVERSITY OF LVIV, UKRAINE.
}

\begin{abstract}
The study is devoted to the development of activities for the development of research activities of students in the learning process in universities. The authors analysed the essence of students' research activities, identified the main tasks of students' research activities and formed a hypothesis that the development of students' research activities in the process of studying at a university will be useful and will be reflected in the dynamics of their creative self-development if it is carried out within the framework of the research development program as a joint activity of a teacher and a student. The authors proposed a model for the development of research activities of students in the learning process, and empirically tested its effect, which confirmed the hypothesis. However, during the experimental phase, some limiting factors were identified.
\end{abstract}

Keywords: Concentrated Learning; Higher Education Institution; Problem-Focused Learning; Research Activity JEL Classification: A22, P36, D83

Received: 28 March 2021

Accepted: 30 April 2021 


\section{Introduction.}

Peculiarities of modern social development, in particular intellectualisation and informatisation, highlight the training of specialists with in-depth knowledge in the field of professional activity and able to navigate the rapidly growing flow of information quickly, adapt to changing conditions and, if necessary - to master a new specialisation, which is impossible without an established research culture.

Ensuring the training of professionals capable of professional growth and professional mobility in the context of informatisation of society and the development of new knowledge-intensive technologies is determined by one of the main goals of any state. It is necessary to prepare students not only to perform future professional functions in the speciality but also to instil in them the need to obtain new information independently, master new knowledge, which is provided by the formed research culture of the individual. Therefore, the educational process in an educational institution should be aimed at students gaining research experience. Thus, the formation of students' research culture becomes not only the most critical indicator of the formed necessary culture of personality but also an indicator of its level of readiness for professional activity in conditions of frequent changes in technology, as well as the self-determination of professional and personal development tasks.

\section{Literature Review.}

The modern period of the development of society is characterised by changes in socio-economic conditions, which entailed the modernisation of the education system, which, in turn, led to the further development of innovative processes in the system of education and upbringing (Prokopenko et al., 2018).

In the context of a changing educational environment, the requirements for the qualifications of university graduates, for their preparedness in the professional and social sense, also change (Karyy \& Knjazevska, 2009; Barnea, 2020). Teaching methods and tools are gradually changing (Tkachenko et al., 2019). Society sets before education the task of training innovative specialists with nonstandard creative thinking and productive activities.

The idea of concentrated education was considered by foreign and domestic scientists (Luo et al., 2019; Romero-Rodríguez et al., 2020); models used in the conditions of general education, vocational and higher education (Ibragimov, 1995; Ibragimov, 2003); as well as the experience of applying the technology of concentrated learning in a university and explores the efficiency and efficacy of concentrated learning is sufficiently substantiated in the works (Brookfield, 2003; Baun, 2015; Andrienko et al., 2018; Puspitasari et al., 2019; Yan \& Sana, 2020).

Research activity is one of the main components of the process of teaching university students, and in current conditions, it already begins with 1-2 courses of study (Svasta et al., 2004; Ginsburg, 2011; Hakobyan et al., 2018). The introduction of educational standards of a new generation poses several problems for higher education, including the question of the continuous development of the individual as a subject of education throughout his life (Ginsburg, 2011). It becomes essential to orient the educational process towards the development of the creative potential of the individual, his self-education, self-development. Therefore, the issues of the development of research activities of students in the process of studying at the HEI become more and more urgent.

\section{The theoretical and methodological basis.}

\subsection{Students' Research Activity.}

When starting to analyse the problem of the development of research activities of university students, it is necessary to turn to the concept of "research activities". As a result of content analysis of the definition of "research activity", we concluded that there is no single point of view in the 
description of the concept in the psychological and pedagogical literature. Scientists reveal its essence through various components, but emphasise that the primary meaning of research in the field of education is that it is educational, pointing out the need to develop the intellectual qualities of a person, creative thinking, therefore when determining the essence, structure and content of research activity, we proceeded from following provisions:

- research activity is a holistic education that includes interrelated components;

- research activity should be considered in the context of the general psychological theory of activity, proceeding from the law on the unity of development of activity and personality (Rubinstein, 1973). Activity is carried out in a conscious, active form; in the process of activity, the character develops, skills and abilities are developed, life experience is acquired.

- research activity is carried out based on an acmeological approach and is considered as a creative activity that allows realising the ideas of self-actualisation and self-development in the process of research activity. Solving problematic creative research tasks is a necessary prerequisite for the development of creativity. The changing personal position concerning the research activity of students is determined by reflection, in the process of which the image "I am a researcher" is formed.

- the integrative developmental approach involves the implementation of the principles of development and integration in learning, allows you to use not only the peculiarities of the problematised content of education in solving the problems of finding ways to effectively develop the research activities of students, but also the mechanism of its implementation at the same time.

The development of research activities of university students will open up opportunities to approach problem-solving in a creative way. In this sense, the issues of the creative development of the individual, the achievement of effectiveness and the potential for creative self-realisation inactivity are covered in detail in the acmeological theory.

The research activity of students is a type of educational activity focused on the development of personal intellectual qualities, creative self-development in the process of solving problem situations, educational and creative research tasks.

Figure 1. The main tasks of the research activities of students

formation of the scientific worldview, mastering the methodology and methods of
scientific research;

The research activity of students is represented by a set of interrelated components: cognitive, axiological, creative, organisational-activity, reflexive-evaluative, which are manifested at a limited, permissible, optimal level. 
Let's define the main tasks of the research activity of students (Fig. 1).

Students' research work can take place both within the educational process and outside it (Fig. 2).

Thus, the hypothesis of the research is as follows: the development of students' research activities in the process of studying at the university will be effective and will be reflected in the dynamics of their creative self-development if it is carried out within the framework of the research development program as a joint activity of a teacher and a student.

\subsection{Organisational and educational conditions for the development of research activities of university students.}

Organisational conditions are considered by us as a set of prerequisites for the organisation of learning and the mechanism of interaction between the subjects of the learning process, providing purposeful research activities of students. Educational conditions are considered as a set of interrelated circumstances that determine the content of the activities of the teacher and students by the goals set.

Concentrated learning is not a new technology in education. The idea of concentrated learning, which has attracted increased interest among educational researchers and practitioners in recent years, is being applied at various levels of the educational system (Luo et al., 2019; RomeroRodríguez et al., 2020).

The experience of applying the technology of concentrated learning in a university and explores the efficiency and efficacy of concentrated learning is sufficiently substantiated in the works (Brookfield, 2003; Baun, 2015; Andrienko et al., 2018; Puspitasari et al., 2019; Yan \& Sana, 2020) and allows its use in a university environment. It should be noted that previously concentrated training was not considered from the standpoint of the development of research activities of university students. However, the broad possibilities of its application at different levels of education and in different conditions were noted.

In the traditional sense (from the standpoint of the system-activity approach), concentrated learning is a specially organised learning process that involves the assimilation of more educational information by students without increasing the study time due to its systematisation (generalisation, structuring), changes in the mechanisms of its assimilation, the forms of its presentation and/or other (different from the traditional) time regime of occupations.

Researchers highlight the conceptual provisions of concentrated learning, which are as follows: overcoming the multidisciplinary nature of the school day, week, semester; long, but, at the same time, available duration of the study of the subject or section of the academic discipline; the continuity of the process of cognition and its integrity (starting with primary perception and ending with the formation of skills); consolidation of the content and organisational forms of the learning process; dispersal of credits and exams; intensification of the educational process in each subject; cooperation of participants in the learning process.

In our opinion, in the traditional technology, the personal aspect is not sufficiently taken into account - the focus on creative self-development. The conventional technology of concentrated teaching is more focused on knowledge-based education, the result of which is in-depth and lasting assimilation of more information by students. Depending on the information to be assimilated, the forms of its presentation change, elements of problem learning are used.

Classifying various ways of organising concentrated education, G. Ibragimov proposes three models used in general education, vocational and higher education (Ibragimov, 1995; Ibragimov, 2003):

- the first model assumes the study of one main subject for a particular time;

- the second model of concentrated learning involves the enlargement of only one organisational unit - a school day, the number of subjects studied is reduced to one or two;

- the third model assumes the expansion of the academic week. 
Figure 2. Students' research work within and outside the educational process

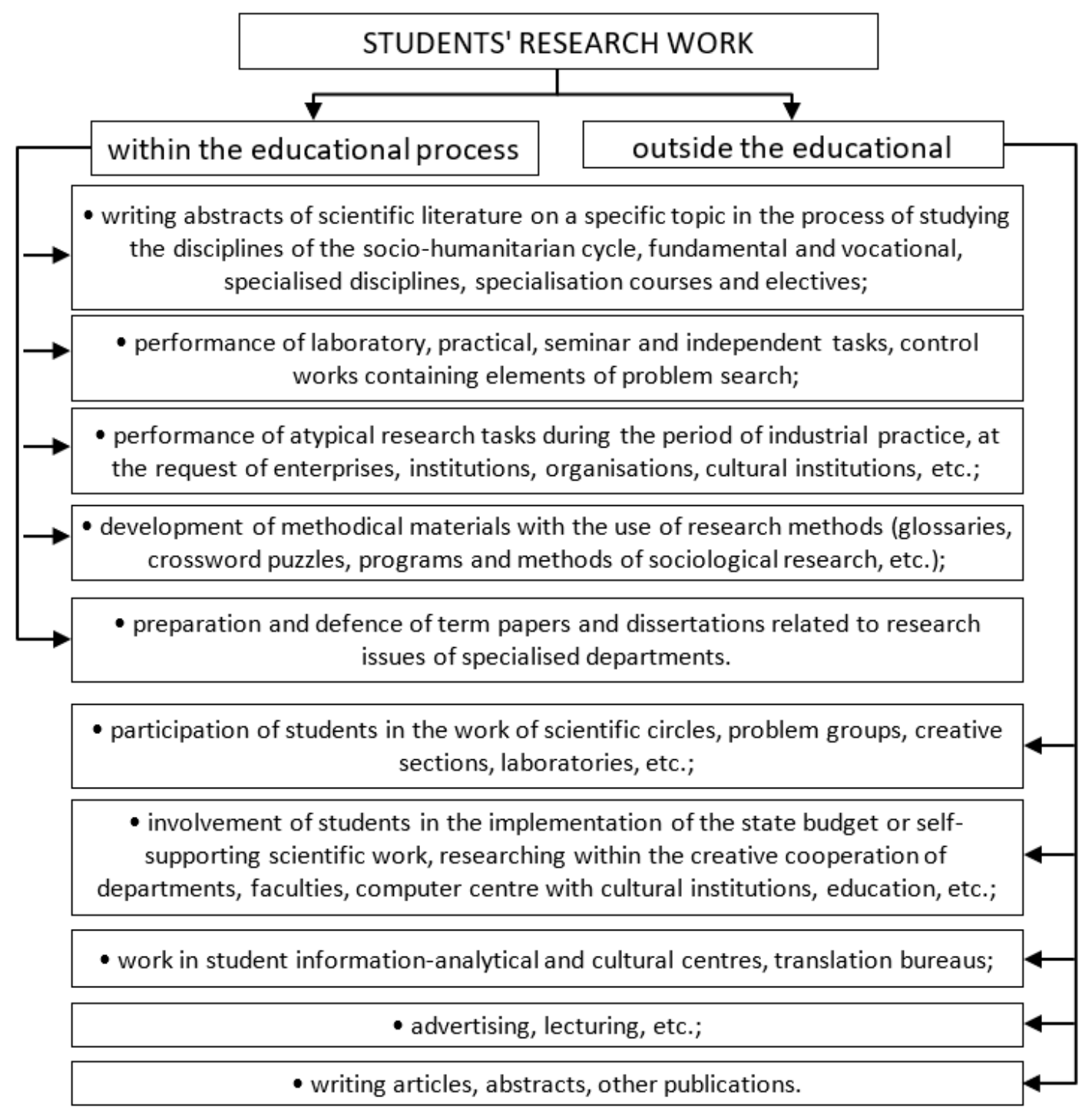

Source: compiled by the authors

From several studies, the second model of concentrated education proposed by G. Ibragimov is the most preferable in the conditions of a university. The authors note that the learning process based on the second model, more fully than in the first and third, takes into account the physiological characteristics of students. Agreeing with the authors, we focus on the second model of concentrated education, by the well-known recommendations for university education, since this does not violate the integrity of the cognitive process, provides psychological comfort and, unlike a traditional organisation, gives an advantage in time.

Thus, the theoretical analysis gives grounds to consider a concentration in time, reflexive comanagement and the gradually increasing complexity of problematisation of the content of the training as justified conditions in the development of students' research activities. The organisational conditions are concentration in time and reflexive co-management, the pedagogical situation is the gradually increasing problematisation of the content of education.

Based on this provision, we supplement the concept of concentrated teaching with the idea of the need to problematise the content of education in the development of research activities of university students and therefore clarify the content of the concept of "problem-focused learning", which is considered as a type of developmental learning based on the gradually increasing complexity of problematisation and integration in teaching carried out in the reflexive co-management of subjects 
of the learning process and concentration in time, the result of which is the creative selfdevelopment of students.

\section{Methodology: Structural and functional model of the development of research activities of students.}

Figure 3. Model of the development of research activities of students

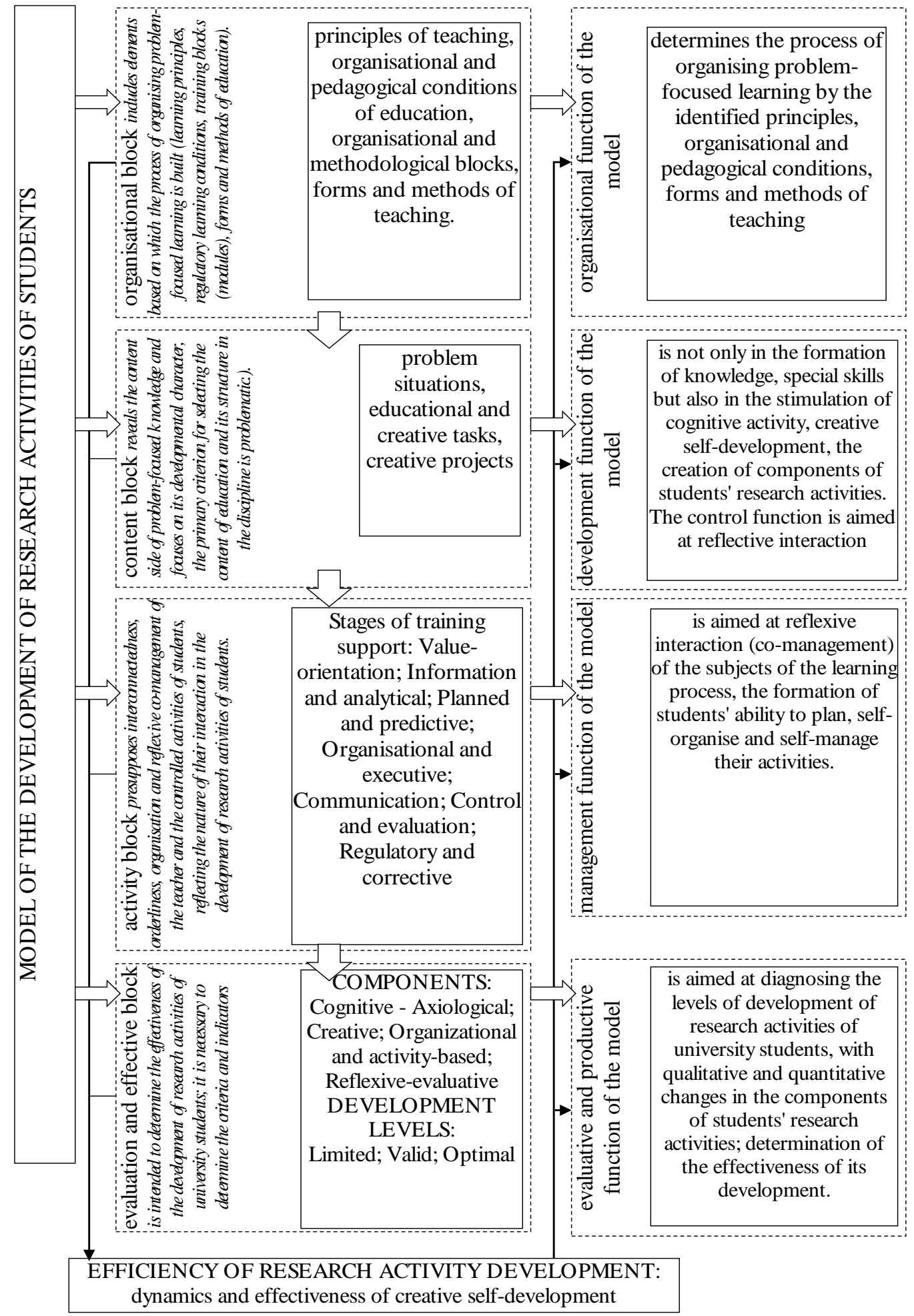

Source: compiled by the authors 
With the help of modelling, it is possible to represent the process under study visually, to systematise knowledge about it, to create integral classifications, and to detail the relationship between components.

We present a structural-functional model of the development of research activities of university students in the process of problem-focused learning (Fig. 3).

The proposed model for the development of research activities of university students in the process of problem-focused learning allows us to present evolution as a joint activity of the teacher and students in the development of problematic content. The model reveals the procedural and substantive aspects of learning through interrelated structural components (organisational, content, activity, evaluation and performance blocks) and functional ties (organisational, developmental, management, evaluation and performance).

\section{Experimental stage and the analysis of results.}

The purpose of the experimental stage of the study was to identify the state of development of research activities of students and the representation of conditions that contribute to its growth in the educational process of the university.

The experimental base of the research was Cherkasy Medical Academy, Municipal Institution of Higher Education "Khortytsia National Educational Rehabilitation Academy", Poltava State Agrarian Academy, Sumy State University and Volodymyr Dahl East Ukrainian National University,

The survey involved 18 teachers and 174 students of 1-5 courses of these universities.

Table 1. Methods and techniques for studying the levels of development of components of research activities among university students

Research
components

\begin{tabular}{ll}
\hline & 1. Observation of the activities of students during training sessions, \\
connitive & 2. Methodology "Assessment of the ability to reason, self-development \\
and self-education & 1. Observation of the activities of students during training sessions, \\
conversations, assessment, self-assessment. \\
2. Methodology "Value orientations" \\
1. Observation of the activities of students during training sessions, \\
conversations, assessment, self-assessment. \\
creative
\end{tabular}

The program of the ascertaining stage of the research was implemented as a diagnosis of the general state of development of research activities of students in the educational process of universities and was carried out in the following areas:

- diagnostics of the development of components of research activities and determination of the levels of development of research activities of students; 
- determination of the content of the activities of teachers, aimed at the development of research activities of students and its actual representation in the educational practice of universities.

To solve the set tasks at the ascertaining stage, the authors used empirical research methods (Table 1).

The students were divided into two groups: where the proposed model for the development of student research activities was not applied (Group A) and where it was applied (Group B). Further, teachers assessed the dynamics of students' research activities, and expert teachers assessed the qualification work of bachelors and masters by components. The summary results are presented in Tables 2-3.

Table 2. The results of evaluating the components of students' research activities (Group A)

\begin{tabular}{|c|c|c|c|c|}
\hline \multirow{3}{*}{ Research components } & \multicolumn{4}{|c|}{$\begin{array}{c}\text { Development of components of students' research activities } \\
\text { (number of people in\%) }\end{array}$} \\
\hline & \multirow{2}{*}{$\begin{array}{c}\text { Insufficient level } \\
0-1\end{array}$} & \multicolumn{2}{|c|}{ Acceptable level } & \multirow{2}{*}{$\begin{array}{c}\text { Optimal level } \\
6-7\end{array}$} \\
\hline & & $2-3$ & 4-5 & \\
\hline cognitive & 15 & 41 & 27 & 17 \\
\hline axiological & 22 & 38 & 20 & 20 \\
\hline creative & 8 & 54 & 16 & 22 \\
\hline $\begin{array}{l}\text { organisational } \\
\text { activity }\end{array}$ & 9 & 27 & 36 & 28 \\
\hline reflective evaluative & 17 & 32 & 36 & 15 \\
\hline
\end{tabular}

Table 3. The results of evaluating the components of students' research activities (Group B)

\begin{tabular}{|c|c|c|c|c|}
\hline \multirow{3}{*}{ Research components } & \multicolumn{4}{|c|}{$\begin{array}{c}\text { Development of components of students' research activities } \\
\text { (number of people in\%) }\end{array}$} \\
\hline & \multirow{2}{*}{$\begin{array}{c}\text { Insufficient level } \\
0-1\end{array}$} & \multicolumn{2}{|c|}{ Acceptable level } & \multirow{2}{*}{$\begin{array}{c}\text { Optimal level } \\
6-7\end{array}$} \\
\hline & & $2-3$ & $4-5$ & \\
\hline cognitive & 12 & 30 & 32 & 26 \\
\hline axiological & 17 & 31 & 24 & 28 \\
\hline creative & 7 & 45 & 24 & 24 \\
\hline $\begin{array}{l}\text { organisational } \\
\text { activity }\end{array}$ & 7 & 19 & 37 & 37 \\
\hline reflective evaluative & 12 & 22 & 42 & 24 \\
\hline
\end{tabular}

For clarity of comparison, we present the results graphically (Fig. 4).

Thus, the hypothesis that the development of students' research activities in the process of studying at a university will be more productive and will be reflected in the dynamics of their creative self-development if it is carried out within the framework of the program for the development of research activities using "problem-focused learning", was empirically confirmed.

The study showed that the earlier the proposed model was applied, the better the results were. It is recommended to use the model of development of research activities of students from the first year of study. The study also showed that there is a category of students who did not perceive the measures for the development of students' research activities; accordingly, it is necessary to take into account factors such as motivation. This proves that research activity makes quite definite requirements for the student's personality: the presence of the ability for creative self-development, reflection, which presupposes concentration (concentration) on a particular object. In general, the growth of the components of students' research activities ranged from $3 \%$ to $60 \%$. 
Figure 4. Model of the development of research activities of students

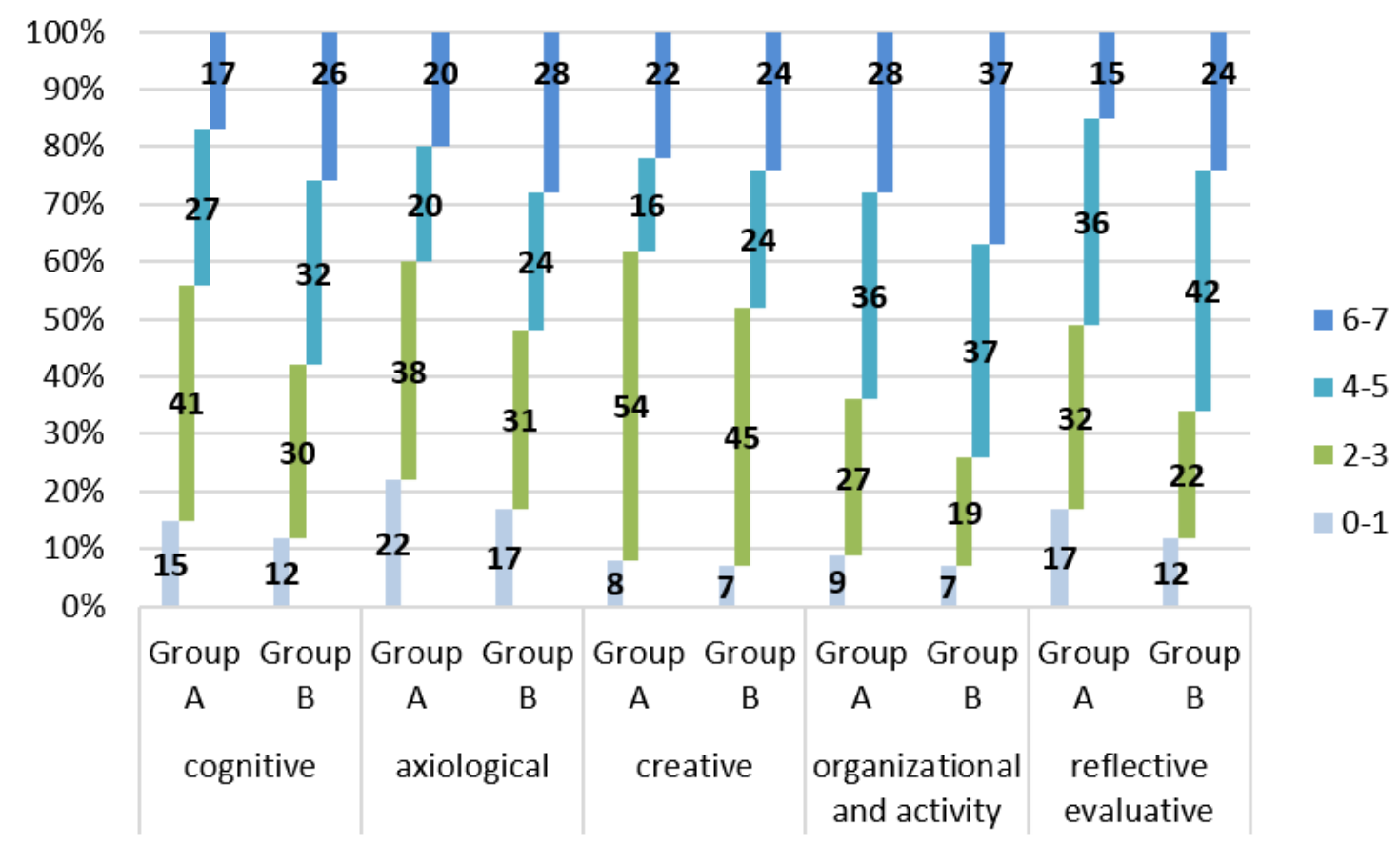

Source: compiled by the authors

\section{Conclusion.}

Development is always individual, which means that the level of development of research activities for different students will be different.

The results of the development of students' research activities are considered through scenarios (forecasts) of local, modular and systemic changes, which make it possible to realise the multivariance and nonlinearity of development paths in the aggregate of necessary and sufficient organisational and pedagogical conditions for problem-focused learning. Research activity makes quite definite requirements for the student's personality: the ability to creative self-development, reflection, which presupposes concentration (concentration) on a particular object, which is why "problem-focused learning" gives effective results.

\section{References}

1. Andrienko A., Efimenko V., Efimenko S. (2018). Organisation of concentrated training in the training of students of a technical university. DOI: 10.23951 / 2307-6127-2018-2-23-31

2. Barnea, A. (2020) Strategic intelligence: a concentrated and diffused intelligence model. Intelligence and National Security, 35(5), pp. 701-716.

3. Baun J. T. (2015). Concentrated Learning: A Linear Approach to Knowledge for Higher Education. Methods in Molecular Biology, 11, pp. 13-26 DOI: 10.1007/978-3-319-10482-9_2

4. Brookfield S. (2003). A critical theory perspective on accelerated learning. New Directions for Adult and Continuing Education, (97), pp. 73-82 DOI: 10.1002/ace.90

5. Ginsburg M. (2011). EQUIP2 State-of-the-Art Knowledge in Education. Teacher professional development. https://www.epdc.org/sites/default/files/documents/EQUIP2\%20SOAK\%20\%20TPD.pdf

6. Hakobyan A. et al. (2018). The efficiency of students' research activities at the food production university. Conference: 11th annual International Conference of Education, Research and Innovation. DOI: 10.21125/iceri.2018.2021 
7. Ibragimov, G. (1995). On the question of the technology of concentrated learning. Specialist, 1, pp. 62-68.

8. Ibragimov, G. (2003). Concentrated teaching in the history of pedagogy. Public education, 9, pp. 87-96.

9. Karyy O., Knjazevska O. (2009). Tasks prioritisation of strategic planning of cities development: experts' approach. Economics \& Sociology, 2(1), pp. 58-66. DOI: 10.14254/2071-789X.2009/2-1/6

10.Luo, Ya., Wong, Yo., Kankanhalli, M., Zhao Q. (2019). Direction Concentration Learning: Enhancing Congruency in Machine Learning. IEEE Transactions on Pattern Analysis and Machine Intelligence, DOI: 10.1109/TPAMI.2019.2963387

11.Prokopenko, O., Kudrina, O., Omelyanenko, V. (2018). Analysis of ICT Application in Technology Transfer Management within Industry 4.0 Conditions (Education Based Approach). CEUR Workshop Proceedings, pp. 258-273.

12.Puspitasari, T., Sari, N., Putr,i Yo., Jannah, N. (2019). Attitude; Physics Learning Concentration. COMPTON Jurnal Ilmiah Pendidikan Fisika, 6(2), 13. DOI: 10.30738/cjipf.v6i2.5850

13.Romero-Rodríguez, J.-M., Aznar-Díaz, I., Hinojo-Lucena, F.-J., Cáceres-Reche, M.-P. (2020). Models of good teaching practices for mobile learning in higher education. Palgrave Communications, $6(1), 80$.

14.Rubinstein, S. L. (1973). Problems of general psychology. Moscow: Education, 424 p.

15.Svasta P. et al. (2004). Undergraduate students' research activities. Conference: Electronic Components and Technology Conference, 2004. Proceedings. 54(2). DOI: 10.1109/ECTC.2004.1320346

16.Tkachenko, V., Kuzior, A., Kwilinski, A. (2019). Introduction of Artificial Intelligence Tools into the Training Methods of Entrepreneurship Activities. Journal of Entrepreneurship Education, 22(6), 110.

17.Yan V., Sana F. (2020). Does the interleaving effect extend to unrelated concepts? Learners' beliefs versus empirical evidence. Journal of Educational Psychology, DOI: 10.1037/edu0000470 